\title{
Comparison of the effects between clonidine and epinephrine added with bupivacine in brachial plexus block.
}

\author{
Dr. A. Ashok Kumar MD ${ }^{1}$, Dr. V. S. Suresh MD² \\ ${ }^{1}$ (Department of anesthesiology, Sri Ramachandra Medical college and Research institute,India) \\ ${ }^{2}$ (Department of anesthesiology, Billroth Hospital,India)
}

\begin{abstract}
:
Background: Demonstration of alpha $\square$ adrenoreceptors in the peripheral nervous system has made to study the effects of various alpha adrenergic drugs with local anesthetics in peripheral nerve blocks. This study is designed to compare the efficacy of clonidine and epinephrine when added to bupivacaine in brachial plexus block. Methods: Forty ASA 1 and 2 patients undergoing upper limb surgeries under supraclavicular brachial plexus block were divided into two groups in a randomized double blinded fashion. Group BA received 5 $\mathrm{mcg} / \mathrm{ml}$ of adrenaline and group BC recieved $\mathrm{mcg} / \mathrm{kg}$ of clonidine along with $30 \mathrm{ml}$ of $0.375 \%$ bupivacaine. Onset of sensory and motor blockade, duration of analgesia, hemodynamic stability were studied in both the groups. Results: Onset of sensory and motor blockade were $6.25 \pm 1.33$ minutes and $3.80 \pm 0.834$ minutes respectively in group $B A$ and $5.85 \pm 1.26$ minutes and $3.55 \pm 1.05$ minutes respectively in group $B C$ which were not statistically significant between the two groups. Duration of analgesia was $7.12 \pm 0.63$ hours in group BA and 12.69 \pm 1.28 hours in group BC which was statistically significant ( $p$ value 0.001). There were no significant difference in the hemodynamic parameters between the two groups. Conclusion: Addition of clonidine to bupivacaine in supraclavicular brachial plexus block provides a significant advantage over epinephrine to bupivacaine in terms of postoperative analgesia without any significant side effects.
\end{abstract}

Keywords: adrenaline, bupivacaine, clonidine, supraclavicular brachial plexus block, upper limb surgeries

\section{Introduction}

Brachial plexus ${ }^{1}$ block was first performed by William Stewart Halsted in 1889 .He directly exposed the brachial plexus in the neck to perform the block and used cocaine. Hirschel first described the percutaneous approach to the brachial plexus. Kulenkampff first described the classical supraclavicular approach to the brachial plexus. Peripheral nerve blocks provide ideal operating conditions when used optimally. They are said to cause least interference with the vital physiological functions of the body and reduced stress response avoiding polypharmacy with an alert awake and co-operative patient when compared to other conventional techniques. Adequately administered regional anesthesia not only provide excellent intraoperative pain relief but also good postoperative analgesia. The demonstration of alpha $\square$ adrenoreceptors in the peripheral nervous system has prompted many investigations on the effects of using various $\square$ adrenergic drugs in combination with local anesthetics in peripheral nerve blocks to prolong post operative analgesia. This study is designed to compare the efficacy of clonidine and epinephrine for prolongation of post operative analgesia when added to bupivacaine in brachial plexus block.

\section{Methods}

After institutional ethical committee approval and written informed consent, a double-blinded randomized prospective clinical study was carried out on 40 American Society of Anesthesiology (ASA) Grade I and II patients of both sex, aged 18-65 years, undergoing various surgeries on the upper limb under supraclavicular brachial plexus block. The study was conducted in two groups of 30 patients each. The patients were randomly assigned using "slips in a box technique" to one of the following groups:

$\mathrm{BA}-30 \mathrm{ml}$ of $0.375 \%$ bupivacaine with $5 \mathrm{mcg} / \mathrm{ml}$ of epinephrine

$\mathrm{BC}-30 \mathrm{ml}$ of $0.375 \%$ bupivacaine with $1 \mathrm{mcg} / \mathrm{kg}$ of clonidine

Patients on adrenoreceptor agonist or antagonist therapy, with known hypersensitivity to local anaesthetic drugs, local infection, coagulation disorders, uncontrolled diabetes mellitus, pregnant and lactating women and pre-existing peripheral neuropathy, were excluded from the study.

On arrival of the patient in the operating room baseline heart rate, ECG, blood pressure and oxygen saturation were recorded. An intravenous access was obtained in the unaffected limb.

All patients received brachial plexus block through the supraclavicular approach by subclavian perivascular technique ${ }^{2}$ by an experienced anesthesiologist different from the one assessing the patient intra- and post-operatively. Both were blinded to the groups. 
Brachial plexus was localized by using a nerve stimulator (plexygon - vygon, france ) connected to a $22 \mathrm{G}$, 50-mm-long insulated stimulating needle (Stimuplex, Braun, Germany). The end point was a motor response with an output lower than $0.5 \mathrm{~mA}$ in the median nerve region.

Under strict aseptic precautions, after local infiltration of $1 \mathrm{ml}$ of $2 \%$ lignocaine in the interscalene groove, $\quad 30 \mathrm{ml}$ of a solution containing local anaesthetic combined with adrenaline or clonidine as mentioned above was injected. Patients were assessed for the onset of sensory and motor blockade every minute, immediately after the administration of the drug. The intra- and post-operative assessment was done by an anesthesiologist who was unaware of the drug used.

Vital signs monitoring : heart rate, non invasive blood pressure, oxygen saturation and sedation score were measured every minute for the first 5 minutes and every 5 minutes thereafter till the end of the surgery. For statistical purpose, they were documented at $0,1,2,5,10,15,30$ minutes thereafter. Sedation is assessed using Ramsay sedation score (6 points)

Sensory blockade was assessed by temperature sensation using ether soaked cotton in the skin dermatomes C4-T2.

Onset of motor blockade was assessed by loss of shoulder abduction. Only patients with complete motor block were included in the study.

Failure of the block to be established even after 20 minutes was taken as block failure. Failure was managed with local anesthetics or general anesthesia as appropriate. Those patients are excluded from the study.

Duration of sensory blockade ( time elapsed between the injection of drug and appearance of pain in the surgical site) was assessed postoperatively using VAS score every 30 minutes for the first six hours and every 2 hours till 24 hours. VAS scale (0-10), where 0 represents no pain and 10 represents worst pain. Inj. Pentazocine $30 \mathrm{mg}$ intramuscularly was given as a rescue analgesic when the pain score was more than 4.

Post operatively heart rate, non invasive blood pressure, oxygen saturation, and sedation scores are recorded at 0, 30 minutes, 1,2,4,6,12 and 24 hours.

Local anesthetic toxic reactions with manifestations like circumoral numbness, tinnitus, twitching, convulsions, etc., were looked for and appropriate measures were taken. Complications associated to technique like intravascular injections, intrathecal injections, hematoma and pneumothorax were looked for intraoperatively and postoperatively and appropriate measures were taken.

\section{Statistical analysis}

All the data were subjected to statistical analysis. The parameters of age and sex were analysed using Chi- square test. Onset time for sensory and motor blockade, duration of surgery and duration of sensory blockade were analysed with LEVENE's test and t- test and the statistical significance estimated. A p value less than 0.05 was considered statistically significant.

\section{Results:}

40 patients posted for upper limb surgeries fulfilling the inclusion criteria were randomly assigned in one of the two groups.

Both groups were comparable in terms of age, sex and weight ( table:1)

TABLE:1 (Patient characteristics)

\begin{tabular}{|c|c|c|c|}
\hline Parameters & Group BA & Group BC & P value \\
\hline Age ( years ) & $32.50 \pm 12.89$ & $32.05 \pm 11.26$ & 0.541 \\
\hline Weight ( Kg ) & $60.90 \pm 7.84$ & $64.30 \pm 8.29$ & 0.191 \\
\hline Sex ( M/F ) & $16 / 4$ & $18 / 2$ & 0.376 \\
\hline
\end{tabular}

Both groups were comparable in terms of type of surgeries also.(table:2)

TABLE:2 (Type of surgical procedure)

\begin{tabular}{|c|c|c|}
\hline Surgery & Group BA & Group BC \\
\hline ORIF & 12 & 9 \\
\hline Post traumatic deformity correction & 4 & 2 \\
\hline External fixation & 1 & 4 \\
\hline Radial head excision & 1 & 2 \\
\hline Sequestrectomy & 1 & 1 \\
\hline Implant exit & 1 & 1 \\
\hline Tension band wiring & 0 & \\
\hline
\end{tabular}


Onset of sensory and motor blockade in the two groups were comparable and there were no statistically significant differenece among the two groups: (table:3)

TABLE : 3 (onset of sensory and motor block)

\begin{tabular}{|c|c|c|c|}
\hline Parameters & Group BA & Group BC & P value \\
\hline Onset of sensory blockade & $6.25 \pm 1.33$ & $5.85 \pm 1.27$ & 0.337 \\
\hline Onset of motor blockade & $3.80 \pm 0.834$ & $3.55 \pm 1.05$ & 0.410 \\
\hline
\end{tabular}

Duration of sensory blockade (fig.1) was longer in group BC(12.69 \pm 1.28$)$ compared to group BA $(7.12+0.63 \mathrm{hrs})$ and the difference was statistically significant ( $\mathrm{p}$ value 0.001$)$

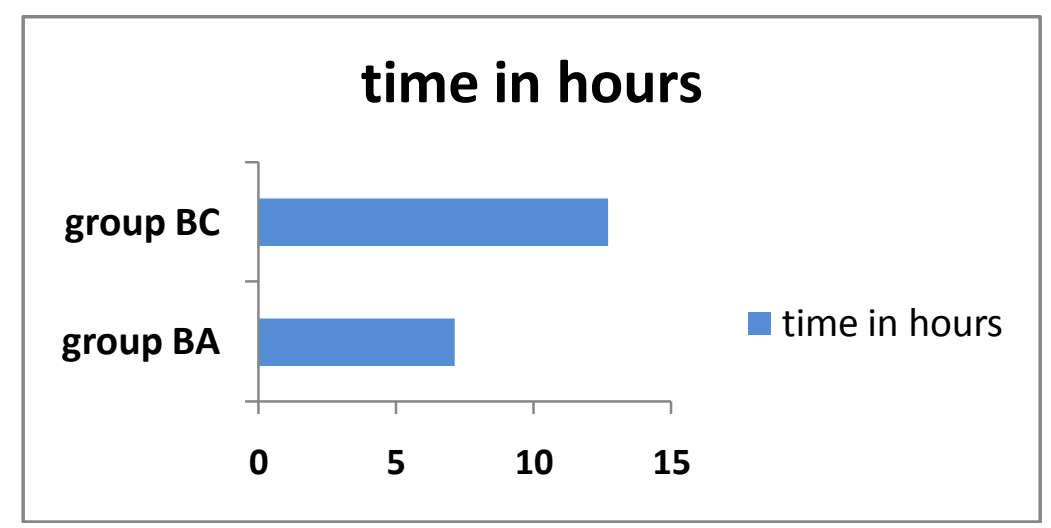

Figure : 1 ( Duration of sensory blockade )

There was no significant difference in the vital signs like heart rate(fig.2\&3), systolic and diastolic blood pressure(fig.4\&5) and oxygen saturation from baseline throughout the surgery and post operative period of 24 hours in the two groups.

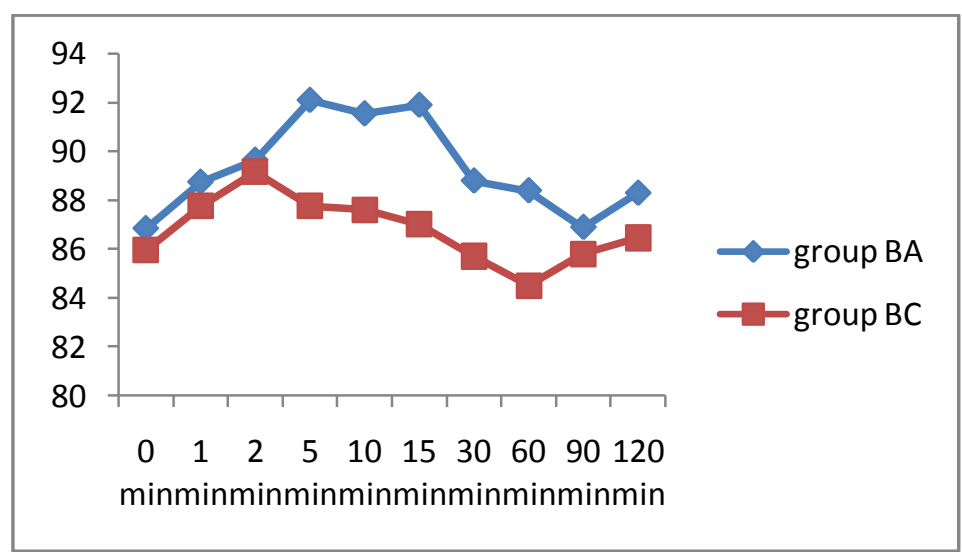

Figure :2 ( intraoperative pulse trend)

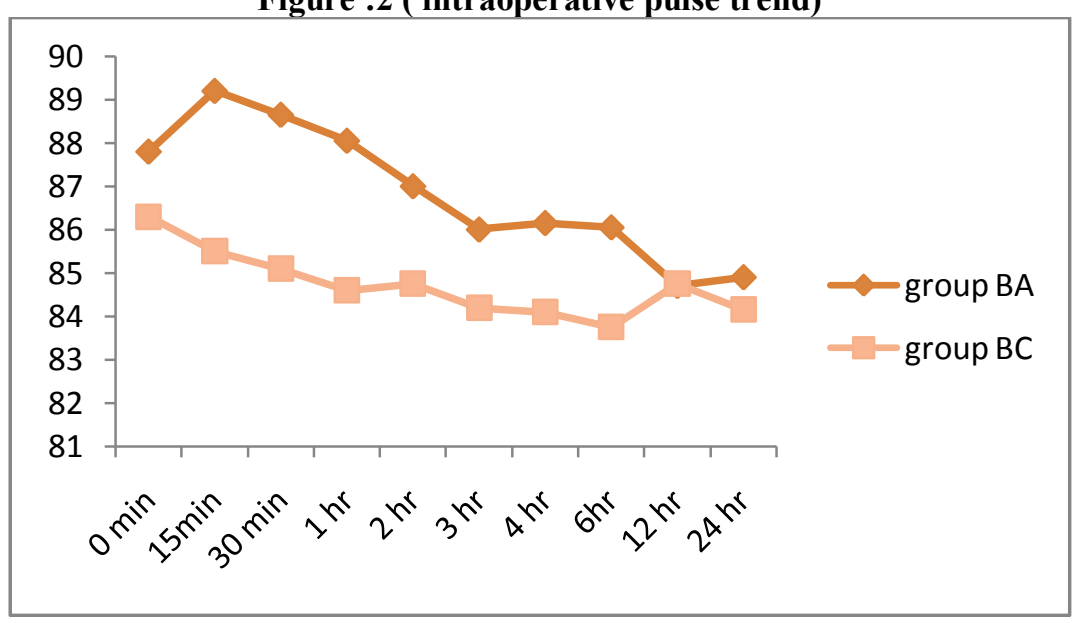

Figure : 3 (postoperative pulse trend) 


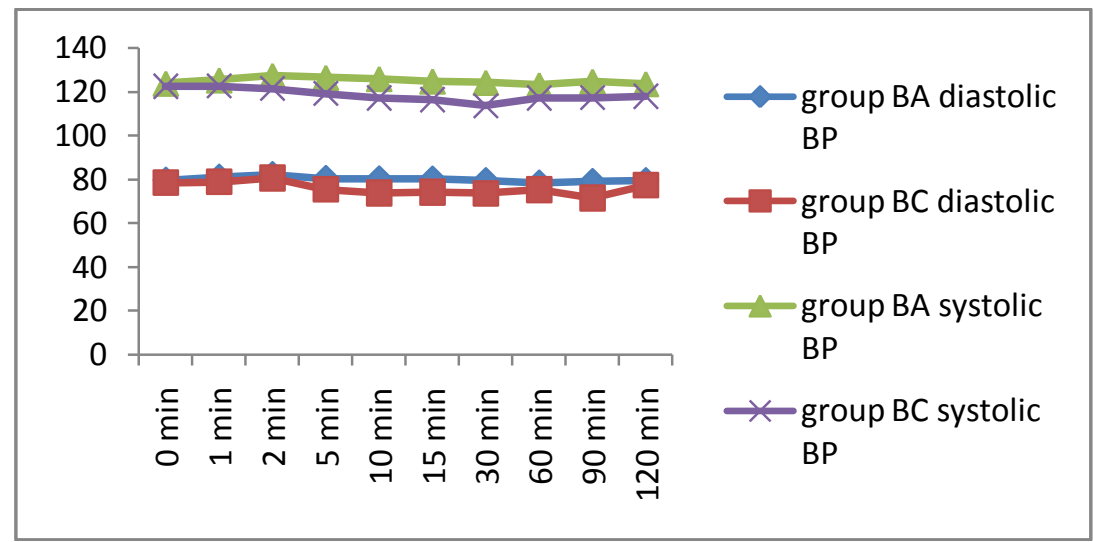

Figure : 4 (intraoperative systolic and diastolic BP trend )

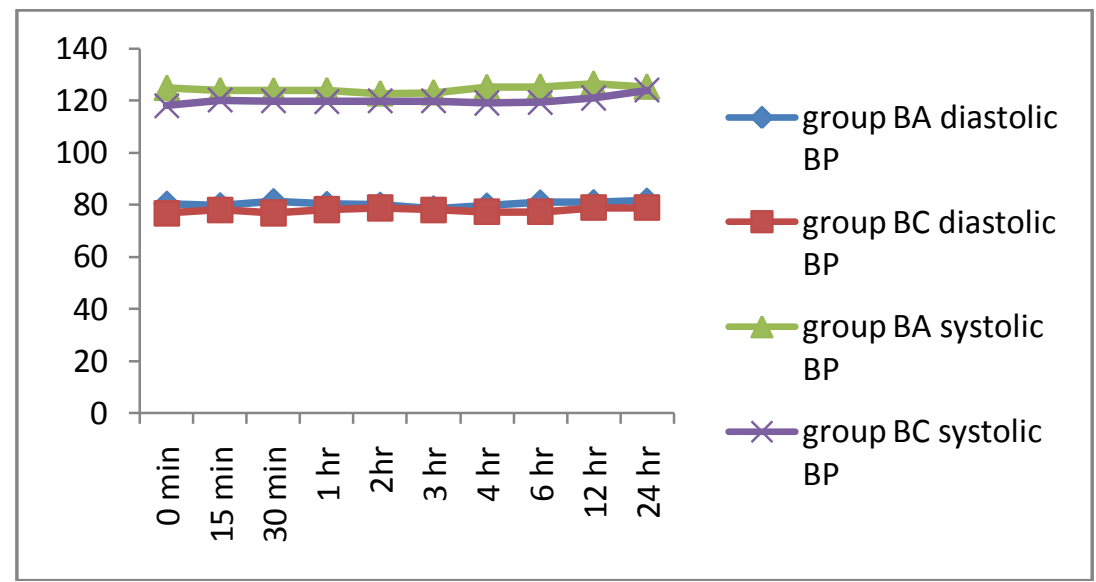

Figure : 5 (postoperative systolic and diastolic BP trend )

None of the patients in the two groups developed any of the side effects like bradycardia, hypotension, sedation, dry mouth, dizziness, arrhythmias, and local anesthetic toxicity.

\section{Discussion:}

Supraclavicular blocks are performed at the level of trunks where the nerves of brachial plexus are tightly packed in a very small surface area, causing the blockade to be rapid in onset, dense and with a high success rate.

In this study $30 \mathrm{ml}$ of $0.375 \%$ bupivacaine is used. This was in agreement with Cherryl et al ${ }^{3}$ in their comparative study of $0.25 \%$ bupivacaine and $0.25 \%$ ropivacaine for brachial plexus block demonstrated a higher incidence of supplementation required and recommended a higher concentration than $0.25 \%$ bupivacaine. It is also reported in various studies that the total volume and concentration of local anesthetic used are crucial factors for the onset of the neural blockade. ${ }^{4,5,6,7}$

Kosugi et al. ${ }^{8}$ examined the effects of various adrenoceptor agonists including dexmedetomidine, tetracaine, oxymetazoline and clonidine, and also an $\alpha_{2}$ adrenoceptor antagonist atipamezole on compound action potential (CAP) recorded from frog sciatic nerve, and found that CAPs were inhibited by $\alpha_{2}$ adrenoceptor agents so that they are able to block nerve conduction. Clonidine and local anaesthetic agents have a synergistic action.

In the study by Casati et al ${ }^{9}$ adding 1 microgram $/ \mathrm{kg}$ of clonidine to local anesthetics for brachial plexus block provided a prolonged duration of sensory analgesia postoperatively without clinically relevant effects on the degree of seation and cardiovascular homeostasis. Hence, in this study clonidine was used at a dose of $1 \mathrm{microgram} / \mathrm{kg}$.

In the study by Eledjam JJ et al ${ }^{10}$ adrenaline 150 microgram was added to $30 \mathrm{ml}$ ( ie., 5 micrograms $/ \mathrm{ml}$ ) of bupivacaine to find the efficacy of alpha agonist on brachial plexus block. Adrenaline was used in the same dose in this study also.

In this randomized, double-blinded trial, we compared adrenaline and clonidine $\left(\alpha_{2}\right.$ agonist $)$ as an adjuvant to Bupivacaine in supraclavicular brachial plexus block, and found that the difference in the onset of sensory analgesia ( $6.25 \pm 1.33$ minutes in adrenaline group and 5.85 \pm 1.26 minutes in clonidine group) and the 
onset of motor blockade ( $3.80 \pm 0.834$ minutes in adrenaline group and $3.55 \pm 1.05$ minutes in clonidine group) were not significant. This correlated with study performed by Eledjam and his colleagues ${ }^{10}$

In this study, there was a significantly increased duration of sensory blockade in the clonidine group $(12.69 \pm 1.28$ hours $)$ than in the adrenaline group $(7.12 \pm 0.63$ hours $)$ which correlated with studies which revealed that Clonidine enhances both sensory and motor blockade of neuraxial and periphera nerves after injection of local anaesthetic solution, without affecting the onset. ${ }^{11,12,13}$ The prolongation of analgesia observed is consistent with other trials performed at the brachial plexus s,10,14,15,16 $^{2}$

In this study there was no significant change in the hemodynamic parameters from the baseline and there were no side effects like bradycardia, hypotension, sedation, dry mouth, dizziness, arrhythmias and local anesthetic toxicity in both the groups. This was consistent with the observation by EL Saied et al ${ }^{17}$, Eledjam JJ et al ${ }^{10}$, and Casati et al ${ }^{9}$. In the study of 28 adult chronic renal failure patients by Adnan et al ${ }^{16}$, addition of clonidine in brachial plexus block decreases both heart rate and blood pressure and had a higher sedation score compared to the control groups.

\section{Conclusion:}

Addition of clonidine to bupivacaine in supraclavicular brachial plexus block significantly improves the duration of sensory analgesia enhancing postoperative pain relief in upper limb surgeries without any hemodynamic alterations and adverse events.

\section{References:}

[1] Techniques of regional anesthesia in Lee's Synopsis of anesthesia 2006:13:419-428

[2] John E Tetzzlaff. Peripheral nerve blocks in Morgan Clinical anesthesiology 2006: 329-337

[3] Cheryl et al. A comparative study of $0.25 \%$ bupivacaine and $0.25 \%$ ropivacaine for brachial plexus block. Regional anesthesia and pain medicine.: 75(40): 1992: 604-611.

[4] Vester-Anderson T, Christiansen C, Sorensen M, Eriksen C. Perivascular axillary Blockade following $40 \mathrm{ml}$ of $1 \% \mathrm{mepivacaine}$ with adrenaline. Acta Anaesthesiol Scand 1982; 26: 519-23.

[5] Vester-Anderson T, Husum B, Lindeburg T, Borrits L, Gothgen I. Perivascular axillary block IV: Blockade following 40 , 50 or 60 $\mathrm{ml}$ of mepivacaine 1\% with adrenaline. Acta Anaesthesiol Scand 1984;28:99-105.

[6] Denson D, Mazoit JX. Physiology, pharmacology, and toxicity of local anesthetic: adult and pediatric considerations. Clinical Practice of Regional Anesthesia. New York: Churchill Livingstone, 1991; 73-105.

[7] Scott DB, McClure JH, Giasi RM, Seo J, Covino BG. Effects of concentration of local anaesthetic drugs in extradural block. Br J Anaesth 1980; 52: 1033-7.

[8] Kosugi T, Mizuta K, Fujita T, Nakashima M, Kumamoto E. High concentrations of dexmedetomidine inhibit compound action potential in frog sciatic nerve without $\alpha 2$ adrenoceptor activation. Br J Pharmacol 2010;160:1662-76.

[9] Casati A, Magistris L, Beccaria P, Cappelleri G, Aldegheri G, Fanelli G. Improving postoperative analgesia after axillary bra chial plexus anesthesia with 0.75\% ropivacaine. A doubleblind evaluation of adding clonidine. Minerva Anestesiol 2001;67:407-12.

[10] Eledjam JJ et al. Brachial plexus block with bupivacaine: effects of added alpha adrenergic agonists: comparison between clonidine and epinephrine. Canadian journal of anesthesiology 1991:38(7);870-5.

[11] El-Hennawy AM, Abd-Elwahab AM, Abd-Elmaksoud AM, El-Ozairy HS, Boulis SR. Addition of clonidine or dexmedetomidine to bupivacaine prolongs caudal analgesia in children. Br J Anaesth 2009;103:268-74

[12] Bhatnagar S, Mishra S, Madhurima S, Gurjar M, Mondal AS. Clonidine as an analgesic adjuvant to continuous paravertebral bupivacaine for post-thoracotomy pain. Anaesth Intensive Care 2006;34:586-91.

[13] Gabriel JS, Gordin V. Alpha 2 agonists in regional anesthesia and analgesia. Curr Opin Anaesthesiol 2001;14:751-3.

[14] Erlacher W, Schuschnig C, Koinig H, Marhofer P, Melischek M, Mayer N, et al. Clonidine as adjuvant for mepivacaine, ropivacaine and bupivacaine in axillary, perivascular brachial plexus block. Can J Anaesth 2001;48:522-5.

[15] Iskandar H, Guillaume E, Dixmérias F, Binje B, Rakotondriamihary S, Thiebaut R, et al. The enhancement of sensory blockade by clonidine selectively added to mepivacaine after midhumeral block. Anesth Analg 2001;93:771-5.

[16] Adnan et al. clonidine as an adjuvant for lidocaine in brachial plexus block in patients with chronic renal failure. Acta Anaesthesiol scand.2005 Apr; 49(4);563-8.

[17] El Saied AH Steyn MP. Ansermino JM , clonidine prolongs the effect of ropivacaine for axillary brachial plexus blockade. Can J Anaesth 2000.Oct: 47(10): 962-7. 